\title{
Gambaran perubahan kadar gula darah pada pasien pra-pasca bedah dengan anestesi spinal menggunakan bupivakain di IBS RSUP Prof. Dr. R. D. Kandou periode Desember 2015 - Januari 2016
}

\author{
${ }^{1}$ Fajrian R. Lubis \\ ${ }^{2}$ Lucky T. Kumaat \\ ${ }^{2}$ Harold F. Tambajong
}

\author{
${ }^{1}$ Kandidat Skripsi Fakultas Kedokteran Universitas Sam Ratulangi Manado \\ ${ }^{2}$ Bagian Anestesiologi dan Terapi Intensif Fakultas Kedokteran Universitas Sam Ratulangi - \\ RSUP Prof. Dr. R. D. Kandou Manado \\ Email: fajrizone@gmail.com
}

\begin{abstract}
Surgical procedure could evoke stress response which will further increase blood glucose levels resulted in hyperglycemia. Spinal anesthesia is assumed to reduce the increase in blood glucose levels. This study was aimed to obtain the profile of blood glucose alterations in pre and postoperative patients with spinal anesthesia using bupivacaine at Central Surgery Installation of Prof. Dr. R. D. Kandou Hospital Manado period December 2015-January 2016. This was a descriptive prospective study with an observational method. Blood glucose levels were examined at pre-operation, as well as 1 hour and 6 hour postoperation at Central Surgery Installation of Prof. Dr. R. D. Kandou Hospital Manado, GMIM Pancaran Kasih Hospital, and Bhayangkara. The results showed that there were 18 patients of spinal anesthesia with bupivacaine. The most frequent percentages were: female (83.3\%), age group 26-35 years old $(55.6 \%)$, sectio caesaria as the type of surgery (83.3\%), duration of surgery 90 minutes (89.9\%), pre-operative blood glucose levels $\leq 70 \mathrm{mg} / \mathrm{dL}$ (55.6\%), 1 hour postoperative blood glucose levels $70-125 \mathrm{mg} / \mathrm{dL}$ (61.1\%), and 6 hour postoperative blood glucose levels $70-125$ $\mathrm{mg} / \mathrm{dl}(82.2 \%)$. Conlusion: There was an alteration in blood sugar levels pre-postoperative manifested as an increased blood sugar level.
\end{abstract}

Keywords: blood glucose level, spinal anesthesia

\begin{abstract}
Abstrak: Tindakan pembedahan dapat menyebabkan timbulnya respon stres yang selanjutnya dapat meningkatkan kadar gula darah bahkan sampai hiperglikemi. Anestesi spinal diduga dapat mengurangi terjadinya peningkatan kadar gula darah. Penelitian ini bertujuan untuk mengetahui gambaran perubahan kadar gula darah pra-pascabedah pada pasien dengan anestesi spinal menggunakan bupivakian di RSUP Prof. Dr. R. D. Kandou Manado periode Desember 2015-Januari 2016. Jenis penelitian ialah deskriptif prospektif dengan metode observasional. Pengukuran kadar gula darah dilakukan saat pra-bedah, serta 1 jam dan 6 jam pascabedah di IBS RSUP Prof. Dr.R.D. Kandou Manado, RSU GMIM Pancaran Kasih dan RS Bhayangkara. Pada hasil penelitian didapatkan 18 pasien dengan anestesi spinal menggunakan bupivakain selama periode Desember 2015-Januari 2016. Distribusi terbanyak pada jenis kelamin perempuan $(83,3 \%)$, kelompok usia 26-35 tahun (55,6\%), jenis operasi sectio caesarea $(83,3 \%)$, durasi pembedahan 90 menit $(89,9 \%)$, kadar gula darah pra-bedah $\leq 70$ $\mathrm{mg} / \mathrm{dL}(55,6 \%)$, kadar gula darah 1 jam pascabedah $70-125 \mathrm{mg} / \mathrm{dL}(61,1 \%)$, dan kadar gula darah 6 jam pascabedah 70-125 mg/dL (82,2\%). Simpulan: Terdapat perubahan kadar gula darah pra-pascabedah berupa peningkatan kadar gula darah.
\end{abstract}

Kata kunci: kadar gula darah, anestesi spinal 
Anestesi spinal merupakan salah satu dari anestesi neuroaksial yang aman dan efektif untuk pembedahan pada daerah perut bagian bawah, ekstremitas bawah, perineum dan inguinal $^{1}$ dengan teknik sederhana dan mudah dikerjakan. ${ }^{2}$ Anestesi spinal diperoleh dengan cara menyuntikkan anestetika lokal ke dalam ruang subaraknoid. ${ }^{2}$ Keuntungan lainnya ialah anestesi spinal lebih baik dalam menekan terjadinya respon stres dibandingkan dengan anestesi umum. ${ }^{3}$

Anestesi spinal menekan respon stres dengan mengurangi pengeluaran katekolamin sehingga meminimalkan respon stres neuroendokrin sebelum insisi sampai periode pascabedah. Trauma pembedahan menyebabkan timbulnya respon stres pada neuroendokrin melalui respon inflamasi lokal dan aktivasi jalur aferen saraf somatik dan viseral. ${ }^{4}$ Akibat respon tersebut, terjadi peningkatan sekresi hormon kortisol, aldosteron, norepinefrin, dan epinefrin yang dikenal sebagai hormon neuroendokrin. Kortisol, glukagon, dan epinefrin akan bekerja secara sinergis dan menyebabkan glukoneogenesis; hal ini menyebabkan terjadinya hiperglikemia.

Respon stres secara alami akan menyebabkan peningkatan kadar gula darah atau keadaan hiperglikemia. Bila kenaikan tidak terkendali selama periode pascabedah maka pasien akan jatuh ke dalam keadaan hiperglikemia pascabedah. ${ }^{5}$ Keadaan tersebut dapat berakhir tidak menguntungkan maupun berefek yang merugikan pasca pembedahan seperti memperlambat waktu pemulihan.

Hasil penelitian Raju et al. ${ }^{6}$ pada tahun 2000 mengenai monitoring gula darh perioperatif memaparkan bahwa kontrol kadar glukosa yang tidak adekuat dapat meningkatkan angka morbiditas dan mortalitas. Selain itu keadaan hiperglikemi dapat dihubungkan dengan timbulnya manifestasi klinis yang buruk baik pada penyandang diabetes maupun tidak.

Penelitian ini bertujuan untuk mendapatkan gambaran perubahan kadar gula darah pada pasien pra-pasca bedah dengan anestesi spinal menggunakan bupivakain di RSUP Prof. Dr. R. D. Kandou periode Desember 2012-Januari 2016.

\section{METODE PENELITIAN}

Jenis penelitian ialah deskriptif prospektif dan observasional. Pengukuran kadar gula darah dilakukan saat pra-bedah, serta 1 jam dan 6 jam pascabedah. Subjek penelitian ialah pasien dengan anestesi spinal menggunakan bupivakain di IBS RSUP Prof. Dr. R. D. Kandou Manado, RSU GMIM Pancaran Kasih, dan RS Bhayangkara selama periode Desember 2015-Januari 2016.

\section{HASIL PENELITIAN DAN BAHASAN}

Pada penelitian yang dilakukan di Instalasi Bedah Sentral (IBS) RSUP Prof. dr. R.D. Kandou, RSU GMIM Pancaran Kasih Manado dan RS Bhayangkara Manado periode Desember 2015-Januari 2016 didapatkan 18 pasien yang menjalani tindakan pembedahan dengan anestesi spinal menggunakan bupivakain.

Karateristik umum subjek penelitian mencakup jenis kelamin, usia, jenis pembedahan dan durasi pembedahan pada pasien dengan anestesi spinal menggunakan bupivakain di Instalasi Bedah Sentral (IBS) ketiga rumah sakit tersebut di atas pada periode Desember 2015-Januari 2016.

Tabel 1 memperlihatkan bahwa jenis kelamin terbanyak ialah perempuan yaitu sejumlah 15 pasien $(83,3 \%)$, sedangkan laki-laki yaitu 3 pasien (16,7\%). Pasien kelompok usia 26-32 tahun yang terbanyak yaitu sejumlah 10 pasien $(22,6 \%)$, diikuti kelompok usia 17-22 tahun sejumlah 4 pasien $(22,2 \%), 46-22$ tahun sejumlah 3 pasien $(16,7 \%)$ dan 36-32 tahun sebanyak 1 pasien $(2,6 \%)$. Durasi pembedahan menunjukkan bahwa pasien yang menjalani pembedahan selama 90 menit memilki jumlah terbanyak yaitu sejumlah 16 orang $(88,9 \%)$, kemudian durasi pembedahan selama 120 menit sejumlah 2 orang $(11,1 \%)$; tidak terdapat pasien pada kelompok pembedahan selama 60 menit. Jenis pembedahan menunjukkan bahwa pasien yang menjalani pembedahan sectio 
caesarea memilki jumlah terbanyak yaitu sejumlah 12 pasien $(83,3 \%)$, herniotomi sejumlah 2 pasien $(11,1 \%)$, dan fistulektomi sejumlah 1 pasien $(2,6 \%)$.

Tabel 1. Distribusi frekuensi pasien pra-pasca bedah dengan anestesi spinal berdasarkan jenis kelamin, usia, jenis pembedahan, dan durasi pembedahan.

\begin{tabular}{lll}
\hline Karakteristik & $\mathbf{N}$ & $\mathbf{\%}$ \\
\hline Jenis kelamin & & \\
Laki-laki & 3 & 16,7 \\
Perempuan & 15 & 83,3 \\
Jumlah & 18 & 100 \\
\hline Usia & & \\
17-22 tahun & 4 & 22,2 \\
26-32 tahun & 10 & 22,6 \\
36-42 tahun & 1 & 2,6 \\
46-22 tahun & 3 & 16,7 \\
Jumlah & 18 & 100 \\
\hline Jenis pembedahan & & \\
Sectio caesarea & 12 & 83,3 \\
Herniotomi & 2 & 11,1 \\
Fistulektomi & 1 & 2,6 \\
Jumlah & 18 & 100 \\
\hline Durasi pembedahan & & \\
60 menit & 0 & 0 \\
90 menit & 16 & 88,9 \\
120 menit & 2 & 11,1 \\
Jumlah & 18 & 100 \\
\hline
\end{tabular}

Berdasarkan beberapa penelitian yang telah dilakukan bahwa anestesi spinal merupakan anestesi neuroaksial paling umum digunakan dalam sectio caesarea karena memungkinan ibu tetap sadar pada saat kelahiran dan mendengar suara tangisan bayinya, sehingga anestesi ini menjadi pilihan utama dalam dunia obsterik ginekologi. ${ }^{4}$ Selain itu sectio caesarea ialah jenis pembedahan tersering pada wanita dan anestesi neuroaksial merupakan teknik yang menjadi prosedur pilihan. ${ }^{15}$

Gambaran kadar gula darah pra-bedah pada pasien dengan anestesi spinal menggunakan bupivakain

Tabel 2 menjelaskan bahwa 10 pasien $(22,6 \%)$ memiliki kadar gula darah dibawah normal $(<70 \mathrm{mg} / \mathrm{dl}), 8$ pasien $(44,4 \%)$ memiliki kadar gula darah normal (70-122 $\mathrm{mg} / \mathrm{dl})$; tidak terdapat pasien dengan kadar gula darah di atas normal ( $\geq 126 \mathrm{mg} / \mathrm{dl}$ ).

Tabel 2. Distribusi frekuensi kadar gula darah pra-bedah pada pasien dengan anestesi spinal menggunakan bupivakain.

\begin{tabular}{lcc}
\hline Kadar gula darah & $\mathbf{N}$ & \% \\
\hline$<70 \mathrm{mg} / \mathrm{dl}$ & 10 & 22,6 \\
$70-122 \mathrm{mg} / \mathrm{dl}$ & 8 & 44,4 \\
$\geq 126 \mathrm{mg} / \mathrm{dl}$ & 0 & 0 \\
Jumlah & 18 & 100 \\
\hline
\end{tabular}

Gambaran kadar gula darah 1 jam pascabedah pada pasien dengan anestesi spinal menggunakan bupivakain

Tabel 3 menjelaskan bahwa 7 pasien $(38,9 \%)$ memiliki kadar gula darah dibawah normal (<70 mg/dl), 11 pasien $(61,1 \%)$ memiliki kadar gula darah normal (70-122 $\mathrm{mg} / \mathrm{dl})$; tidak terdapat pasien dengan kadar gula darah di atas normal $(\geq 126 \mathrm{mg} / \mathrm{dl})$.

Tabel 3. Distribusi frekuensi kadar gula darah 1 jam pascabedah pada pasien dengan anestesi spinal menggunakan bupivakain.

\begin{tabular}{lcc}
\hline Kadar gula darah & $\mathbf{N}$ & \% \\
\hline$<70 \mathrm{mg} / \mathrm{dl}$ & 7 & 38,9 \\
$70-122 \mathrm{mg} / \mathrm{dl}$ & 11 & 61,1 \\
$\geq 126 \mathrm{mg} / \mathrm{dl}$ & 0 & 0 \\
Jumlah & 18 & 100 \\
\hline
\end{tabular}

Gambaran kadar gula darah 6 jam pascabedah pada pasien dengan anestesi spinal menggunakan bupivakain

Tabel 4 menjelaskan bahwa 2 pasien $(27,8 \%)$ memiliki kadar gula darah dibawah normal $(<70 \mathrm{mg} / \mathrm{dl}), 13$ pasien $(82,2 \%)$ memiliki kadar gula darah normal (70-125 mg/dl); tidak terdapat pasien dengan kadar gula darah di atas normal ( $\geq 126 \mathrm{mg} / \mathrm{dl}$ ).

Tabel 4. Distribusi frekuensi kadar gula darah 6 jam pascabedah pada pasien dengan anestesi spinal menggunakan bupivakain.

\begin{tabular}{lcc}
\hline Kadar gula darah & $\mathrm{N}$ & $\%$ \\
\hline$<70 \mathrm{mg} / \mathrm{dl}$ & 2 & 27,8 \\
$70-122 \mathrm{mg} / \mathrm{dl}$ & 13 & 82,2 \\
$\geq 126 \mathrm{mg} / \mathrm{dl}$ & 0 & 0 \\
Jumlah & 18 & 100 \\
\hline
\end{tabular}


Gambar 1 memperlihatkan secara keseluruhan tentang kadar gula darah prabedah, 1 jam pascabedah dan 6 jam pascabedah pada pasien dengan anestesi spinal menggunakan bupivakain.

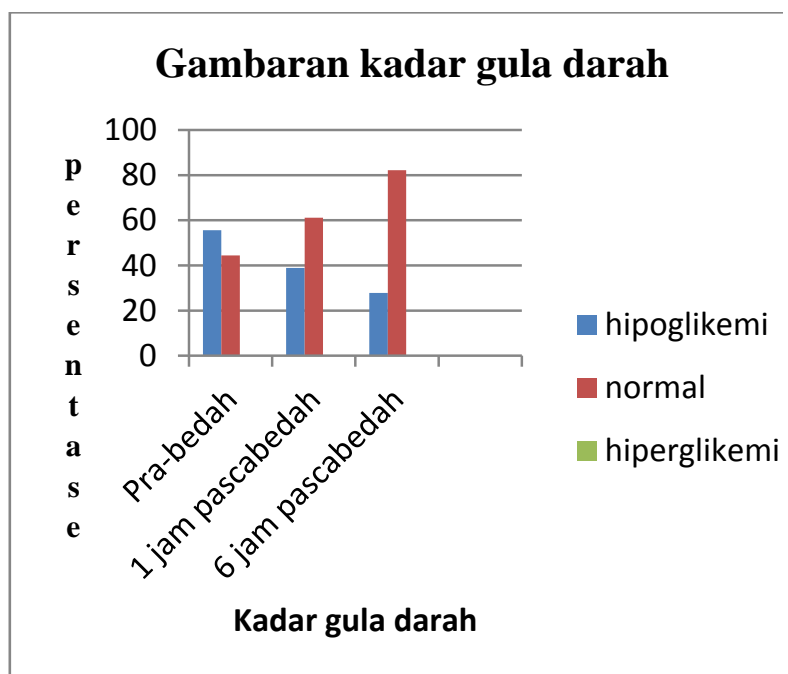

Gambar 1. Diagram gambaran kadar gula darah pasien dengan anestesi spinal menggunakan bupivakain

Nilai perubahan kadar gula darah pada pasien dengan anestesi spinal menggunakan bupivakain

Tabel 5 menjelaskan bahwa 11 pasien $(61,1 \%)$ mengalami peningkatan kadar gula darah dan sebanyak 7 pasien $(38,9 \%)$ mengalami penurunan kadar gula darah dari pra-bedah ke 1 jam pasca bedah.

Tabel 5. Perubahan kadar gula darah dari prabedah ke 1 jam pascabedah pada pasien dengan anestesi spinal menggunakan bupivakain.

\begin{tabular}{lcc}
\hline $\begin{array}{l}\text { Pra-bedah ke 1 jam } \\
\text { pasca bedah }\end{array}$ & N & \% \\
\hline Meningkat & 11 & 61,1 \\
Menurun & 7 & 38,9 \\
Jumlah & 18 & 100 \\
\hline
\end{tabular}

Tabel 6. Perubahan kadar gula darah dari 1 jam pascabedah ke 6 jam pasca bedah pada pasien dengan anestesi spinal menggunakan bupivakain.

\begin{tabular}{lcc}
\hline Kadar gula darah & N & \% \\
\hline Meningkat & 17 & 94,4 \\
Menurun & 1 & 2,6 \\
Jumlah & 18 & 100 \\
\hline
\end{tabular}

Tabel 6 menjelaskan bahwa 17 pasien $(94,4 \%)$ mengalami peningkatan kadar gula darah dan sebanyak 7 pasien $(2,6 \%)$ mengalami penurunan kadar gula darah dari 1 jam pascabedah ke 6 jam pascabedah.

\section{Nilai mean kadar gula darah pasien dengan anestesi spinal menggunakan bupivakain}

Tabel 7 memperlihatkan gambaran nilai mean (rerata) kadar gula darah pada pasien dengan anestesi spinal menggunakan bupivakain

Tabel 7. Nilai rerata kadar gula darah.

\begin{tabular}{lc}
\hline Kelompok kadar gula darah & $\begin{array}{c}\text { Rerata kadar } \\
\text { gula darah } \\
\text { (mg/dL) }\end{array}$ \\
\hline $\begin{array}{l}\text { Kadar gula darah pra-bedah } \\
\text { Kadar gula darah 1 jam pasca } \\
\text { bedah }\end{array}$ & 62,9 \\
$\begin{array}{l}\text { Kadar gula darah 6 jam pasca } \\
\text { bedah }\end{array}$ & 81,1 \\
\hline
\end{tabular}

Tabel 7 dan Gambar 2 memperlihatkan rerata kadar gula darah pra-bedah 62,9 $\mathrm{mg} / \mathrm{dl}$; rerata kadar gula darah pada 1 jam pasca bedah $72,4 \mathrm{mg} / \mathrm{dl}$; dan rerata kadar gula darah 6 jam pasca bedah $81,1 \mathrm{mg} / \mathrm{dl}$. Terdapat perubahan rerata kadar gula darah berupa peningkatan nilai rerata kadar gula darah dari pra-bedah ke 1 jam pasca bedah sebesar $9,86 \%$ dan peningkatan nilai rerata kadar gula darah dari 1 jam pascabedah ke 6 jam pascabedah sebesar 10,6\%.

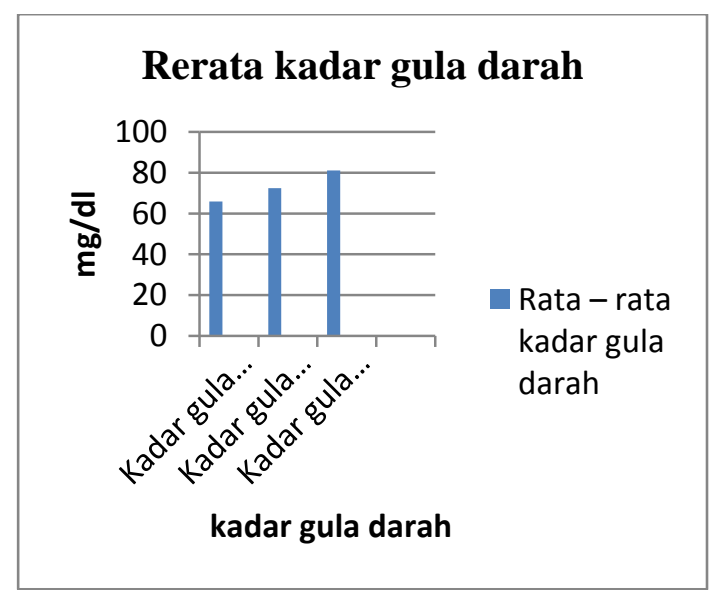

Gambar 2. Rerata kadar gula darah 
Hasil penelitian ini sesuai dengan penelitian sebelumnya bahwa tindakan pembedahan akan menyebabkan respon stres yang berkaitan dengan peningkatan kadar gula darah. Di sisi lain anestesi spinal sebagai blok neuroaksial mampu menghambat respon stres walau bukan secara keseluruhan. ${ }^{5}$ Pada penelitian ini, tidak terdapat peningkatan kadar gula darah melewati $120 \mathrm{mg} / \mathrm{dl}$ hingga dapat jatuh pada keadaan hiperglikemi pascabedah. ${ }^{4}$

Hasil yang diperoleh berbeda dari hasil penelitian sebelumnya bisa disebabkan karena adanya perbedaan pada waktu pengukuran kadar gula darah menggunakan accu-chek. Pada penelitian ini peneliti mengukur kadar gula darah pada prabedah, 1 jam pascabedah dan 6 jam pascabedah. Terdapat dua fase dalam respon metabolik terhadap respon stres yaitu fase ebb dan fase flow yang dapat mempengaruhi kadar gula darah dari jam pertama pascabedah hingga beberapa minggu kemudian. Disamping itu, hasil berbeda bisa disebabkan blok simpatik dan somatik aferen yang tidak komplit atau inadekuat menyebabkan peningkatan aktivitas pada pituitari dan peningkatan sekresi kortisol dari korteks adrenal sehingga mempengaruhi kortikotropin yang memiliki pada peningkatan kadar gula darah. $^{5}$

\section{SIMPULAN}

Berdasarkan hasil penelitian dapat disimpulkan bahwa terdapat perubahan kadar gula darah pra-pascabedah pada pasien dengan anestesi spinal menggunakan bupivakain berupa peningkatan kadar gula darah tetapi tidak bermakna karena belum melewati batas normal kadar gula darah.

\section{SARAN}

1. Perlunya pemantauan kadar gula darah selama perawatan pascabedah.

2. Setiap pasien yang akan pra-bedah perlu diketahui kadar gula darahnya untuk mencegah kejadian hiperglikemia pascabedah

3. Perlunya perhatian khusus pada ibu hamil yang akan menjalani pembedahan untuk mencegah terjadinya keadaan hipoglikemia.

\section{DAFTAR PUSTAKA}

1. Pitkaen M. Spinal (subarachnoid) blockade. In: Cousins M, Bridenbaugh PO, Carr DB, Horlocker TT, editors. Cousins and Bridenbaugh's Neural Blockade in Clinical Anesthesia and Pain Medicine (4th ed). Philadelphia. Lippincott Williams \& Wilkins, 2008; p. 213-6.

2. Latief SA, Surjadi K, Dachlan R. Petunjuk Praktis Anestesiologi (2nd ed). Jakarta: Bagian Anestesiologi dan Terapi Intensif Fakultas Kedokteran Universitas Indonesia, 2002; p. 109-11.

3. Singh $M$. Stress response and anaesthesia: altering the peri and post operative management. Indian J Anaesth. 2003;47(6):427-34.

4. Butterworth JF, Mackey DC, Wasnick JD. Morgan \& Mikhail's Clinical Anesthesiology: Regional anesthesia and pain management (5th ed). United State: Lange, 2013; p. 937-48.

5. Desborough JP. The stress response to trauma and surgery. $\mathrm{Br} \mathrm{J}$ Anaesth. 2000;85(1):109-17.

6. Raju TA, Torjman MC, Goldberg ME. Perioperative blood glucose monitoring in the general surgical population. $\mathbf{J}$ Diabetes Sci Technol. 2009;3(6):12827. 